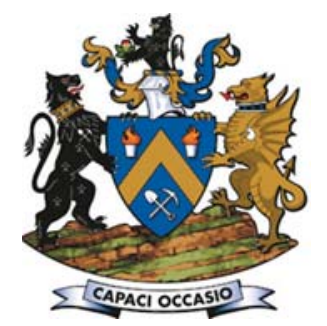

\title{
A systemic study of mining accident causality: an analysis of 91 mining accidents from a platinum mine in South Africa
}

\author{
by J. Bonsu*, W. van Dyk ${ }^{\dagger}$, J-P. Franzidis*, F. Petersen, and \\ A. Isafiade*
}

\section{Synopsis}

This paper aims to demonstrate how a systemic approach can be applied to the analysis of the causes of accidents in South African mines. The accident analysis framework used was developed previously by the authors from the combination of the Mark III version of the Swiss Cheese model, Incident Cause Analysis Method (ICAM), the Nertney Wheel model, and safety management principles. Data on 91 accidents occurring from 2010 to 2012 at the site of a platinum mine in South Africa were used to populate the newly developed framework. The results obtained show that while routine violations ( $45 \%$ of all accidents analysed) were the most common form of human error, problems in the physical environment of workers were the most common workplace factor $(39.6 \%$ of all accidents analysed). Furthermore, inadequate leadership was found to be the most common systemic factor responsible for accidents $(51.6 \%$ of all accidents analysed). Some workplace factors were more commonly associated with particular unsafe acts than others, and some systemic factors were more associated with particular workplace factors than others. The outcome of this study demonstrates that systemic factors, rather than human errors and violations, are the chief causes of accidents in the mining sector.

Keywords

mine safety, systemic factors, accident causality, human error.

\section{Introduction}

The mining industry is a very important sector of the South African national economy. A major factor threatening the sustainability of this industry is mining accidents, which frequently result in injuries or deaths, destruction of property, and pollution of the environment. In the past, mining accidents have led to the shutdown and threat of shutdown of mines (Ryan, 2008; Mail and Guardian, 2011). The country stands the risk of incurring significant losses if the mining industry continues to experience shutdowns. In 2012, the mining sector accounted for R262.7 billion (equivalent to US $\$ 32.83$ billion) representing $8.3 \%$ of GDP directly, on a nominal basis (Chamber of Mines of South Africa, 2013).

Mining safety is a global concern and has attracted significant international attention. This has precipitated various studies into different aspects of mining. Unfortunately, human error has been blamed for the majority of these accidents. A study by the US Bureau of Mines found that human error is the cause of almost $85 \%$ of all accidents (Patterson and Shappell, 2008). In Australia, it is the cause of two out of every three occupational accidents (Patterson and Shappell, 2008). Various mining companies maintain that they run efficient systems, and hence the behavioural problems of workers are to blame for most accidents. An understanding of accident causality could be a major step in the quest to reduce accidents. Only with a good understanding of the accident process can effective remedies can be designed.

The Swiss Cheese model (Reason, 1990) has indisputable value in analysing industrial accidents. The model is based on the fundamental components of all successful production systems, viz. decision-makers, line management, preconditions for effective work, production activities, and safeguards against known hazards. Effective and safe production can be achieved only when the right decisions are taken at each level of the production system. The process leading to an accident starts when inappropriate decisions taken at the management level are propagated through the various components of the production system. These decisions create 'holes' in the barriers put in place to prevent accidents. In this model, an accident is seen as a combination of unsafe acts by front-line operators and latent conditions in the organization (systemic factors).

Techniques based on this model have been applied to the aviation (Li and Harris, 2006; Li et al., 2008) and railway industries (Baysari et al., 2008), and more recently to the mining industry (Patterson and Shappell, 2010; Sanmiquel et al., 2010; Lenné et al., 2011).

\footnotetext{
* Department of Chemical Engineering, University of Cape Town, South Africa.

+ Arete Consultants (Pty) Ltd.

F Faculty of Engineering and the Built Environment, University of Cape Town, South Africa.

(C) The Southern African Institute of Mining and Metallurgy, 2017. ISSN 2225-6253. Paper received Apr. 2015; revised paper received April. 2016.
} 


\section{A systemic study of mining accident causality: an analysis of $\mathbf{9 1}$ mining accidents}

Patterson and Shappell (2010) used a modified version of the Human Factors Analysis and Classification System (HFACS) to analyse mining accidents in Queensland, Australia. The results showed that although human error was involved in most of the accidents, other factors such as existing conditions, unsafe leadership climate, and organizational factors also contributed. Sanmiquel et al. (2010) used a framework that incorporated multiple causal factors such as behavioural, medical, equipment, training, and environmental causes to analyse accidents from the Spanish mining industry. The results show that factors (environmental, training, and equipment) other than human behaviour also contributed to mining accidents. Lenne et al. (2011) used the HFACS framework to analyse accident reports from Australia. The results showed that, in several instances, failure in one part of the system led to failures in other parts. For example, a failed organizational climate was commonly associated with inadequate supervision, and inadequate supervision was commonly associated with failure in team resource management. The results obtained from different studies using different methods support the view that a systemic approach to accident causality is the right way to tackle mining-related safety issues.

Although results from previous studies conducted in other countries are very insightful, the context in which these studies were conducted is very different from that of South Africa and hence they may be of limited applicability. These differences usually manifest themselves in the level of mechanization of the industry, the type of mining (ultra-deep vs shallow), and socio-economic factors such as migrant labour and the educational level of the miners.

Although there have been some studies (Ashworth and Peake, 1994; Moseme et al., 2003; Maisa and Pienaar, 2011) into accident causality in South African mines, to the best knowledge of the authors there has not been any structured study linking human error to upstream causal (systemic) factors. A systemic study of mining accident causality in South Africa would be useful for a full appreciation of the dynamics of safety issues in the industry.

This paper aims to demonstrate how a systemic approach can be applied to the analysis of the causes of accidents in South African mines. In this study, a newly developed accident analysis framework was used to analyse 91 accidents from a platinum mine in South Africa. The subsequent sections explain the framework, the methodology applied, and the results obtained.

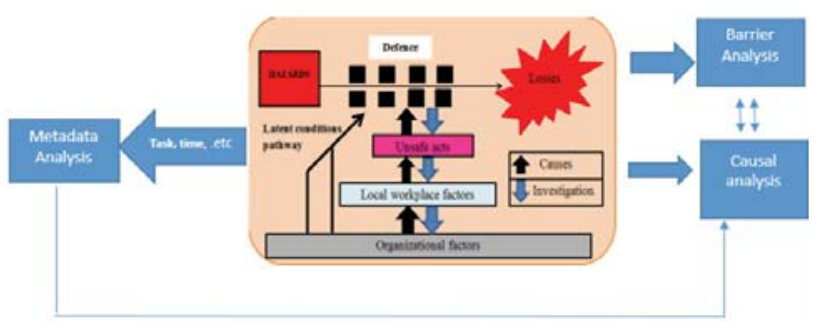

Figure 1-Accident analysis framework developed from the Swiss Cheese model (Bonsu et al., 2015)

\section{Method}

\section{Accident analysis framework}

A newly developed analysis framework (Bonsu et al., 2015) was used to analyse accident data from a South African platinum mine. The framework has three major sections, namely causal analysis, agency and barrier analysis, and metadata (Figure 1).

\section{Causal analysis section}

The first section of the framework provides a structure for the analysis of accident causality. It is divided into three levels, viz. proximal causes, workplace factors, and systemic factors. The first level of the causal section, which is proximal causes, seeks to identify the human error that led directly to the failure of controls/defences, and thereby to the accident. These errors are subdivided into slips and lapses, mistakes, violations, and non-human causes. The workplace factors level, which is the second level of the causal section, addresses error- or violation-producing conditions in the workplace that contribute to accidents. The subcategories are competent people, safe work practices, fit-for-purpose equipment, and a controlled work environment (Bullock, 1979). Systemic factors comprises the third layer of the causal section, and it identifies ways in which the actions of management contribute to error- or violation-producing conditions in the workplace, leading to an accident. The subcategories include training and competence, contractor management, design, management of change, hazard identification, monitoring and auditing, maintenance management, resource provision, strategic decision/planning, risk management, leadership, work scheduling, and emergency response.

\section{Agency and barrier analysis}

This section of the framework records information on the accident-causing agencies (mode of injury) involved in each of the accidents analysed. The accident classification codes employed in Item 12 of the South African Mines Reportable Accidents Statistics System (SAMRASS) were used to categorize the accidents analysed (Department of Mineral Resources, 2007). Under Item 12 of the SAMRASS code, accident-causing agencies identified include fall of ground; machinery, tools, and equipment; transport and mining; conveyance accidents; electricity; fire; explosives; and caving.

Safety barriers broken were recorded because knowledge of the nature of barriers broken, as well as how and why they were breached, provides insight into the causes of accidents. Safety barriers can be defined as any means (physical or non-physical) instituted to prevent, control, or mitigate accidents (Hollnagel, 2008). The need for safety barriers in industry arises from the fact that due to the nature of some industrial activities is not always possible to remove all hazards by design. In such situations the safety of employees is ensured by placing a barrier between them and the hazard. This implies that the harm from a hazard reaches a target only when there is no safety barrier to prevent it or the barriers put in place were not effective. The nature of the safety barriers in place also tells a lot about the nature of the industry and the kinds of unsafe acts that will be most prevalent in such an industry. 


\section{A systemic study of mining accident causality: an analysis of 91 mining accidents}

\section{Metadata}

In addition to data on barriers and accident-causing agencies, the new framework was designed to capture specific metadata about the accidents analysed. Metadata can simply be defined as information (e.g. data) describing other data. This data was chosen to elucidate other factors that may have influenced these accidents, e.g. the knowledge that most accidents occur at a particular time of day could help in understanding why those accidents are happening.

\section{Data}

The data used in this study comprised 91 investigation reports on accidents that occurred on a platinum mine in South Africa between 2010 and 2012. The platinum mining sector has the second highest annual fatalities (Chamber of Mines of South Africa, 2012).

\section{Coding and data analysis}

Accident data from the reports was coded into the new framework. The different categories used for classification in the newly developed framework were identified from sections of the accident reports such as the description of the event, sketches or photographs of incidents, immediate and basic causes, and recommendations made. This was done so as to prevent over-representation of a single incident. Other relevant metadata such as time of the accident, qualification of victim etc. were also recorded. The pivot table and chart tools in Microsoft Excel® 2010 were used to categorize and summarize the data. The filter tool was used to single out sections of the needed information.

\section{Results}

\section{Accident characteristics}

The accidents in the reports analysed involved one fatality, 27 serious injuries, 31 lost time injuries, and 32 minor injuries. A serious injury is defined as any injury that leads to a permanent disability or renders the victim unable to work for 14 days or more. A lost time injury is defined as any injury that renders the victim unable to work for 1 to 13 days. A minor injury is any injury that renders the victim unable to work for up to one day. These definitions are in harmony with the standards prescribed by SAMRASS (Department of Mineral Resources, 2007).

The analysis of the reports showed that the most common accident-causing agencies (mode of injury) were hand tools/equipment (20\%), falls of ground (15\%), falling of material/rolling rock (14\%), slipping and falling (13\%), and manual handling of material (11\%). The most common tasks being performed by victims at the times of the accidents were drilling (25\%), engineering tasks (24\%), transportation of people $(11 \%)$, and manual handling (11\%).

The study also discovered that most barriers broken in the process of accidents occurring were administrative in nature (standards, risk assessments, and supervision). This shows that barriers and safeguards put in place to prevent accidents are not engineered (not self-enforcing), thus creating room for human error.

\section{Accident causality}

Table I summarizes the accident causal factors identified in this study. Each category in the framework (such as mistake, violation, physical environment etc.) was counted a maximum of once as the cause of an accident. However for some accidents more than one kind of unsafe act (such as a mistake and a violation) was identified. This accounts for the total number of unsafe acts being greater than the total number of accidents (see Table I). The percentages within each category were calculated using the total number of accidents (91) rather than the number of counts under a level. Because of this, none of the categories under a level sum to $100 \%$.

Unsafe acts were identified in $98.9 \%$ of the accident reports analysed. This comes as no surprise, since the mine is very labour-intensive. Workplace and systemic factors were involved in $97.8 \%$ of cases analysed.

From Table I it can be seen that the most common form of unsafe act identified was routine violation (identified in $45 \%$ of all cases), followed closely by mistakes (43\%) and then slips and lapses (30.8\%). The most prevalent workplace factor identified was the physical environment $(39.6 \%$ of all accidents analysed), closely followed by the behavioural environment (34.1\%).

Unsafe work practices, fit-for-purpose equipment, and competence of people were also identified as contributing significantly to accidents. Leadership was the most common systemic factor identified in this study. This is due to the already-stated fact that most safety barriers put in place were not self-enforcing and therefore needed the input of leaders before they could function. Other systemic factors identified as leading to accidents at the mine were hazard identification, maintenance management, and management of change. Hazard identification was cited as a causal factor in instances when an accident happened even though the accident victims followed company procedures. This was seen to be as a result of a deficiency in the original hazard identification process during the formulation of the procedures.

Table I

\section{Accident causal factors}

\begin{tabular}{l|c|c}
\hline Framework category & Frequency & Percentage \\
\hline Direct causes & & \\
Slips and lapses & 29 & 30.8 \\
Mistakes & 39 & 43.0 \\
Routine violation & 41 & 45.0 \\
Deviant violation & 2 & 2.2 \\
\hline Workplace factors & & \\
Competent people & 18 & 19.8 \\
Fit-for-purpose equipment & 16 & 17.6 \\
Physical environment & 36 & 39.6 \\
Behavioral environment & 31 & 34.1 \\
Unsafe work practices & 14 & 15.4 \\
\hline Systemic factors & & \\
Management of change & 11 & 12.1 \\
Leadership & 47 & 51.6 \\
Training and competence & 7 & 7.7 \\
Contractor management & 8 & 8.8 \\
Risk management & 9 & 9.9 \\
Design & 8 & 8.8 \\
Maintenance management & 7 & 7.7 \\
Hazard identification & 18 & 19.8 \\
Monitoring and auditing & 5 & 5.5 \\
Strategic decision & 0 & 0.0 \\
Work scheduling & 4 & 4.4 \\
Emergency response & 0 & 0.0 \\
\hline
\end{tabular}




\section{A systemic study of mining accident causality: an analysis of $\mathbf{9 1}$ mining accidents}

Specific examples of management of change include instances in which loss of qualified employees (either due to resignation or leave) and changes in task environment or task requirements) were not managed properly, leading to accidents.

\section{Links between various accident causal factors}

Some workplace factors were more commonly associated with particular unsafe acts than others (see Figure 2).

From Figure 2, the most common workplace factor identified with routine violations was behavioural environment ( $72 \%$ of the workplace factors identified with behavioural environment). This means that most routine violations occurred because of the absence of a system that frowns upon violations by workers and different levels of leadership. Other workplace factors such as physical environment, competent people, fit-for-purpose equipment, and unsafe work practices were barely identified as reasons for the violation of the company's standards and procedures.

The workplace factors identified with mistakes are much more diversified. While competent people (29\%) and unsafe work practices $(27 \%)$ were the two leading workplace factors, fit-for-purpose equipment (12\%), physical environment $(22 \%)$, and behavioural environment $(10 \%)$ were also significant. Most cases of competent people identified with mistakes in this study included lack of experience, inadequate skill level, not undergoing planned task observation, and inadequate personnel. These situations obviously left mineworkers vulnerable to committing mistakes. Most instances of unsafe work practices identified with mistakes in this study included nonexistence of standards for a specific task, and situations in which standards did not fully cover tasks. Confined spaces, poor illumination, and poor ground conditions were the most common examples of physical environment identified with mistakes. These conditions usually exacerbated the effect of the mistakes rather than being the actual cause. The presence of tools unsuited to the task requirement (e.g. short pinch bars), or equipment not functioning properly, or the absence of the needed tool, are specific examples of instances of fitfor-purpose equipment identified with mistakes in this study. Behavioural environment was cited in situations where uncoordinated activities and lack of communication led to mistakes.

Physical environment (79\%) was the most common workplace factor identified with slips and lapses. The existence of harsh environmental conditions makes victims liable to such slips and lapses. This finding differs from those

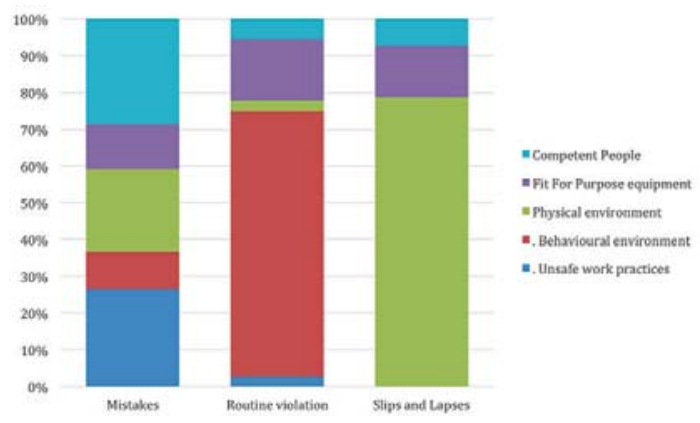

Figure 2-Distribution of unsafe acts based on workplace factors reported by Lenné et al. (2011), who found that adverse physiological states (synonymous with health problems) had significant causal relationships with skill-based errors (synonymous with slips and lapses). However, in this study, very little was known about the state of the victim (such as psychological problems) as far as the tendency to cause slips and lapses is concerned. This was because the accident reports were not structured to capture such details. Situations such as modifications to equipment and equipment without handles are examples of the few occasions when (un) fit-forpurpose equipment led to slips and lapses.

Figures 3-7 shows that some systemic factors were more associated with particular workplace factors than others. The most common cause of unsafe work practices was hazard identification (see Figure 3). This usually led to hazards not being catered for in design of procedures, which put workers at risk while performing tasks. This condition, the authors believe, created situations in which existing work procedures did not protect workers from hazards. Management of change and monitoring and auditing were identified in a few instances as contributing to unsafe work practices. Management of change was identified as a contributing factor to unsafe work practices when an initially adequate procedure became inadequate due to changes in the usual work condition (e.g. working in a new section). Monitoring and auditing was also cited when there was cause to believe that the unsafe work practice was due to failure of monitoring of systems.

Resource provision was the main systemic factor (29\%) identified with instances of fit-for-purpose equipment (see Figure 4). In most of these cases workers had no choice but to use available tools. The second most prevailing situation (25\%) was scenarios in which leadership (mainly shift bosses and team leaders) did not report shortage of equipment or leaders gave workers tools that were unsuited to the task. Maintenance management was identified as a significant contributory factor (17\%) to issues of fit-forpurpose equipment in this study. The poor maintenance of existing equipment usually affected the ability of the tools to safely perform the task. Poor design, management of change, and risk management each made minor contributions to the situations of fit-for-purpose equipment at the workplace. Examples of poor design of equipment identified in this study included equipment lacking handles and lack of protection against hazards while using equipment. Scenarios in which poor risk and change management were cited included

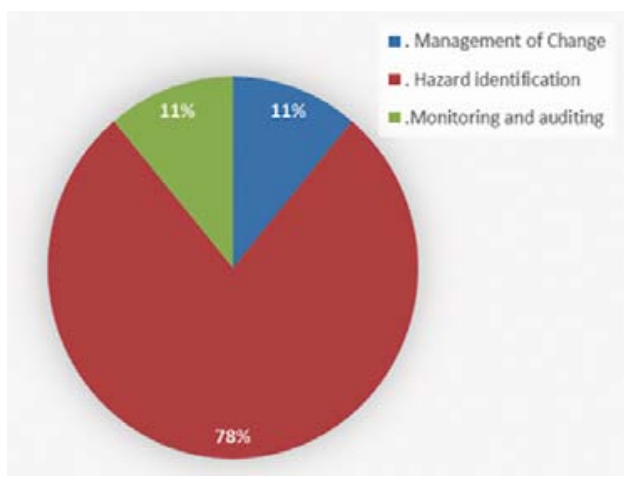

Figure 3-Systemic factors associated with unsafe work practices 


\section{A systemic study of mining accident causality: an analysis of 91 mining accidents}

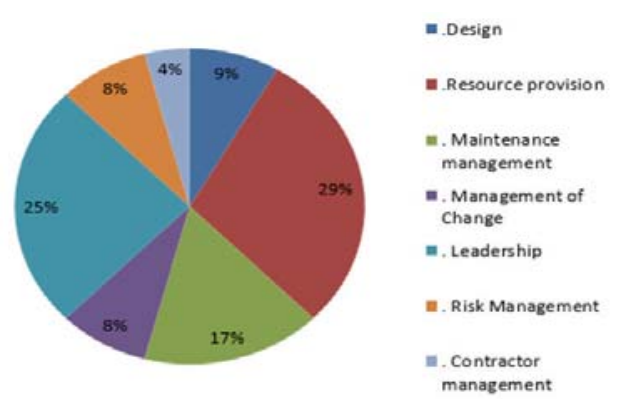

Figure 4-Systemic factors associated with fit-for-purpose equipment

situations where modifications to existing

equipment/operation introduced new risks, thereby leading to accidents and situations in which reported equipment deficiencies were not dealt with.

Training and competence and leadership were the most common systemic factors ( $32 \%$ for each) identified with instances of competent people (Figure 5). Common situations classified under training and competence included inadequate training and the absence of training for particular tasks. These situations made workers incompetent for the task assigned. Examples of leadership lapses identified with the absence of competent people included failure to conduct planned task observation and failure to supervise inexperienced workers. This was usually identified as leading to accidents involving inexperienced workers. Other systemic factors identified with competent people were monitoring and auditing, work scheduling, and hazard identification, contractor management, and management of change. While incompetent contractors performing tasks was the main link between contractor management and competent people, common examples of management of change included the effect of a worker's official leave on the training of other workers. An example of management of change found in this study was the situation where the impact of shift leaders failing to provide adequate training to workers was not identified until it led to an accident.

This is seen as an indication of a poor monitoring system. A specific example of poor work scheduling was the presence of an inadequate workforce on voluntary shifts. This, in the authors' opinion, reduced the workers' ability (competence) to execute the task assigned to them. An example of hazard identification identified in this study is when workers behaved in a risky manner because of lack of knowledge of a particular hazard in the operating procedures.

Leadership was the most common (75\% of all systemic factors associated with the workplace factor) identified with behavioural environment (Figure 6). Poor leadership was identified at different levels, from section manager, shift boss, and technical head, to team leader. There were many instances when wrong acts were committed in the presence of leaders. This indicates a problem with safety culture. The systemic factors identified with physical environment were leadership, risk management, design, hazard identification, maintenance management, and change management (see Figure 7). Examples of leadership identified in this study as a cause of situations under physical environment included failure to correct known problems at the workplace and failure to enforce thorough workplace inspections.

\section{Discussion}

\section{Accident characterization}

The characterization of accidents provides the basis for understanding the results obtained in this study. The results show that the mode of operation in the mine is very labourintensive; hence workers operate in very close proximity to hazards. As already stated, drilling (24\%), engineering tasks (25\%), and manual handling (11\%) were the most accidentprone tasks. These tasks are manual and are performed using handheld tools like drilling machines, crowbars, and spanners, placing workers very close to the hazards. This view on the issue of exposure to hazards is reinforced by the types of slipping and falling accidents identified in this study. The CSIR of South Africa has predicted that South African mines will be labour-intensive for many years to come (CSIR,

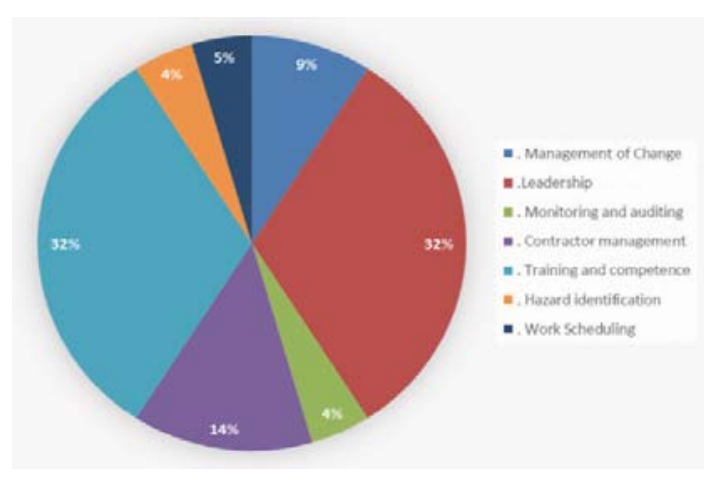

Figure 5-Systemic factors associated with competent people

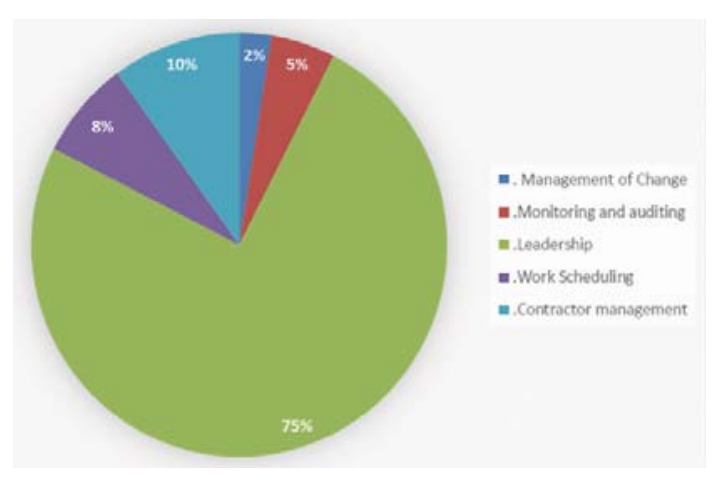

Figure 6-Systemic factors associated with behavioural environment

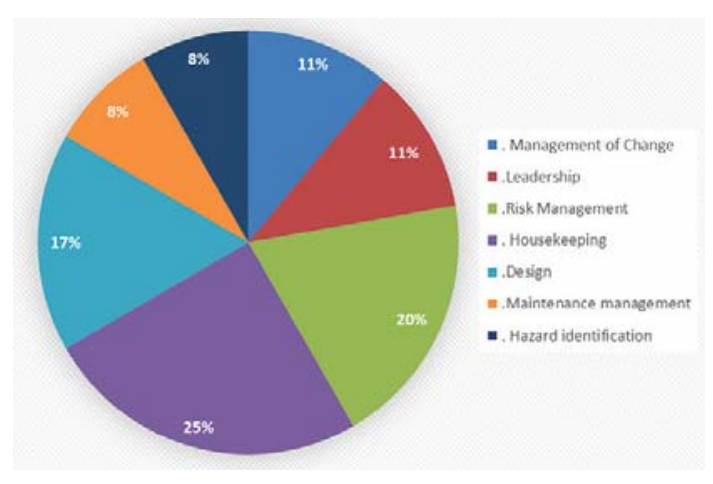

Figure 7-Systemic factors associated with physical environment 


\section{A systemic study of mining accident causality: an analysis of $\mathbf{9 1}$ mining accidents}

2007). This supports the view that a significant number of accidents are due to the proximity between workers and hazards.

The level of exposure of humans to hazards in engineering tasks (e.g. maintenance) is similar across most industries. Reason (1997) stated that while some industries have been able to automate most functions, thereby moving workers further away from hazards, maintenance-related activities remain one field where there is still a significant level of contact between humans and hazards. He argued that close contact between people and technical components makes up the single largest human factor problem when facing most hazardous technologies.

An inference that can be drawn from the above argument is that the activities at the mine under study that involve close contact between humans, technological components of the system, and hazards are partly responsible for the high involvement of human error in most accidents. This view is supported by the results obtained in the barrier analysis section of this study, which showed that standards, risk assessment, and supervision are the three barriers that were frequently breached. It can thus be deduced that safety at the mine is heavily dependent on the workers' willingness to obey rules, the supervisors' ability to enforce the rules, and the workers' ability to perceive danger in their environment and avoid it. This also seems to suggest that the equipment being used for task is not fit for purpose.

The results from the accident characterization were compared with those of Ashworth and Peake (1994), Sanmiquel et al. (2010), Kecojevic et al. (2007), Cawley (2003), and Lenné et al. (2011). Ashworth and Peake (1994), who studied causes of accidents in the South African platinum and gold industries, also identified falls of ground, trackbound equipment, slipping and falling, and scrapers and winches as frequent causes of accidents. This implies that the profile of accidents in the mine used as a case study in this research is a reasonably good representation of the accident profile of the South African platinum industry as a whole.

Sanmiquel et al. (2010), whose study was based on Spanish mines, stated that most of the underground accidents reported were caused by falling and collapsing objects, followed by victims being trapped between objects. These accidents are very similar to fall of ground, falling material, or rolling rock identified in this study as some of the most common agencies. Kecojevic et al. (2007) reported that from $37 \%$ to $88 \%$ of the annual mine fatalities in the USA were attributable to mine equipment (e.g. haul trucks, belt conveyors, front-end loaders, and miscellaneous equipment). This may be due to the fact that mining in the USA is more mechanized. Cawley (2003) reported that electrical-related accidents represent the fourth-highest cause of mining accidents in the USA. Lenné et al. (2011) found that operations involving surface mobile equipment, working at heights, and electrical equipment were the chief causes of mining accidents in Australia. However, it is worth stating that neither the present study nor that of Ashworth and Peake (1994) (which are both based on South Africa) identified electrical equipment as a significant cause of accidents in South African mines. The differences in the dominating types of accident-causing agencies between the different studies highlights fundamental differences in safety concerns between the mining industry in South Africa and in more developed countries. While key safety concerns in the aforementioned countries may be how to deal with residual hazards associated with a high level of mechanization of mining activities, the South African mining industry is still faced with the challenge of removing well-known hazards (e.g. falls of ground) which have existed in its operations for a long period.

In summary, the results from the accident characterization in this study have clearly shown the potential of the current work systems on the mine to serve as a precursor for many human-induced accidents. The following sections proceed to discuss the pertinent human factor issues identified in these accidents.

\section{Causal analysis}

The analysis of accident causality showed that routine violations were the most common unsafe acts. This is consistent with the observation that most barriers broken were administrative in nature. Routine violations were widespread among all workers, and this indicates a higher cause. In an earlier study on mine accidents by Patterson and Shappell (2010) in Australia, skill-based errors (slips and lapses) formed the bulk of the unsafe acts committed. The high number of violations identified in the current study relative to that of Patterson and Shappell (2010) can be attributed to the difference in the two mining systems.

While the accident reports used in the current study were all from an underground mine, Patterson and Shappell (2010) used reports from a balance of underground and opencut coal mines, underground and opencut metal/nonmetal mines, quarries, and processing plants. Surface mining is usually mechanized, and processing plants are mostly automated, and these factors help to separate people from hazards. It is therefore not surprising that the most common human errors encountered in the Patterson and Shappell (2010) study were inadvertent operations (slips and lapses).

Although the language barrier is probably a contributing factor to the errors and violations observed, deductions made in this study were limited to the evidence in the accident reports. The coders were not privy to the educational level of the operators, hence such extrapolations could not have been made.

\section{Links among causal factors}

The accident causality analysis also suggested that poor leadership is the root cause of most of the violations identified in this study. This is based on the fact that the most common workplace factor identified with most routine violations was behavioural environment, i.e. an environment in which people who violated the standards or procedures were not corrected either by co-workers, team leaders, or shift supervisors. These results are similar to findings reported by Lenné et al. (2011), where violations had a high association with crew resource management (i.e. lack of teamwork, failure of leadership, and also how the social environment of the worker is managed). Furthermore, on behavioural environment, Paul and Maiti (2008) reported that the presence of social support (from co-workers and leadership) reduces the possibility of workers having a negative attitude. These results illustrate the need for creating a work environment that does not support violations. According to Reason et al. (1998), this situation is due to the 


\section{A systemic study of mining accident causality: an analysis of $\mathbf{9 1}$ mining accidents}

existence of conflicting goals. For instance, there can be a conflict between organizational goals in terms of rules and regulations (e.g. conducting mid-shift barring) and meeting a personal goal (e.g. achieving a production bonus). Ensuring that safe behaviour is psychologically rewarding is a viable option in addressing such a gross culture of impunity. Creating a social environment where wrong behaviour is eschewed and the concordance of individual and organizational goals is maximized were the recommendations of Reason et al. (1998) to deal with violation-inducing environments. Based on the current study, it can be deduced that lapses in leadership/supervision are the root causes of routine violations. The accident analysis sheet did not provide enough information about why the various levels of leadership failed in their supervision duty. This may be due to other factors such as excessive administrative duties.

The authors are of the opinion that high production pressures exerted on workers might have contributed to the high routine violation rates identified (note that this was not stated in any of the reports used in this study). One of the most common routine violations identified in this study is failure to do mid-shift barring. Workers were supposed to stop working and bar down any hanging or loose rocks. Workers are unlikely to conduct this barring operation if they are behind in completing the shift's work. In the analysis of the accident reports, the authors came across instances of routine violations occurring in the presence of supervision. This indicates the possibility of conflicting goals. This view is shared by Ashworth and Peake (1994), who conducted separate research on the South African gold and platinum mining industry, and the findings of a study by Lenné et al. (2011) which reported significant causal relationships between violations and adverse mental states. Adverse mental state as used in the Lenné et al. (2011) study describes situations of mental fatigue, which may happen as a result of long hours of work.

The results (Figure 2) also showed that the causes of mistakes identified in this study are more complicated and diverse than the other unsafe acts. This view is influenced by the fact that the causes of mistakes were distributed across the five workplace factors. This seems to suggest that training is not a panacea for dealing with the occurrence of mistakes. The systemic factors leading to these workplace factors are also diverse, as explained previously. This situation may be due to the complex nature of mining hazards, which makes it difficult to predict all possible scenarios of danger. Inadequate communication amongst workers and poor risk/situational assessment were commonly identified as leading to mistakes. This is similar to the findings of Patterson and Shappell (2010) and Ashworth and Peake (1994). Such inadequate communications leads to wrong decisions. The study of Patterson and Shappell (2010) identified procedural error and faulty risk and situational assessment as the most common decision errors (synonymous with mistakes). Ashworth and Peake (1994) identified inadequate examination/inspection of the work environment as the cause of $21.4 \%$ of all accidents analysed. The authors of the current study agree with the reasons given by Ashworth and Peake (1994) for ineffective risk assessments by mineworkers, which include inadequate methods of examination and the use of ineffective tools and inadequate training system. The study discovered that existing working procedures on barring are equivocal on how far to stand when barring rock or exactly what constitutes an unsafe environment. Tools used in barring, such as pinch bars, equally put workers in danger. This leads to the deduction that hazard identification, management of change, provision of resources, and risk management are the systemic factors that need to be dealt with if mistakes leading to falls of ground are to be reduced. The study of Lenné et al. (2011) identified technological environment (synonymous with fitfor-purpose equipment) as the main cause of decision errors (mistakes). This tends to agree with the findings of this study, that the nature of the tools being used affects the quality of workers' judgement. Saleh and Cummings (2011) proposed the concept of defence-in-depth as a better way of dealing with hazards in mines. The merits and demerits of defence-in-depth have been discussed elsewhere (Reason, 2000).

The authors of the current study propose the consideration of the use of technologies such as automation for making-safe procedures (Teleka et al., 2012), virtual reality training (Squelch, 2001), and in-stope netting to increase the level of safety in the presence of complex hazards.

Most slips and lapses identified in this study were deemed to be caused by the presence of a non-supporting physical environment. This is not really surprising, considering the harsh environmental conditions to which workers are exposed. The effect of the physical environment on the performance of mineworkers corroborates the studies of Sanmiquel et al. (2010) and Patterson and Shappell (2010) which, although conducted in different countries (Spain and Australia, respectively), identified the working environment as a major factor affecting the performance of mineworkers. The results show that the systemic factors that lead to physical environment problems can be categorized into two major groups. While design and hazard identification occur during the construction of the workplace, risk management, maintenance management, and change management occur during day-to-day mining operations. While factors such as design and hazard identification usually create permanent conditions such as narrow stopes, factors such as poor risk management, maintenance management, and management of change degrade an originally suitable working environment. Both of these make it difficult for workers to carry out tasks efficiently. This scenario validates Reason's (1990) explanation of the varying nature of holes in various organizational structures that lead to accidents. While the first group of holes (design and hazard identification) lie dormant in the organization for a long time, the second group (risk management and maintenance management problems) are usually created as production activities are carried out. This also confirms Reason's (1997) description of safety as not being something an organization has, but what it does.

The role of leadership/supervision has been discussed in detail in this study due to the number of instances in which it was identified as a causal factor in various incidents. Leadership, as referred to in this study, involves shift bosses, team leaders, and sectional supervisors. Due to the administrative nature of barriers used by the company, the role of leadership in the safety of operations cannot be overemphasized. Different levels of leaders are in charge of operationalization of various components of safety 


\section{A systemic study of mining accident causality: an analysis of $\mathbf{9 1}$ mining accidents}

management such as provision of resources (making sure equipment moves from storage to workers), enforcing rules, conducting risk analysis on new tasks, and ensuring safe housekeeping. It is no wonder that leadership was identified as a root cause of most workplace factors. The level of leadership lapses encountered in various accidents hints at deeper systemic problems. The authors believe a further investigation of the factors that affect the performance of leaders is needed.

In conclusion, the study has clearly identified the complexity of accident causality. However, the results suggest that with positive safety measures and a constant commitment to safety, a safer workplace can be achieved. A foundation has also been laid for the use of a larger data-set for a cross-commodity (different type of mines and products) analysis. This will bring to light the broader picture of the systemic factors to be considered.

\section{Limitations}

As with all post-hoc analysis, the efficacy of the technique depends on the genuineness of the information in the accident reports. The authors have no means of crosschecking such information.

\section{Conclusion}

A framework developed from the Swiss Cheese model (Reason 1990, 1997) has been used to analyse accidents in the South African mining industry. The results have shown that owing to the nature of operations in the mining industry in South Africa, routine violations are the main unsafe acts leading to accidents, although other unsafe acts are also significant. The physical environment is the most common workplace factor and leadership and systemic factor identified in most accidents. Some workplace factors are more commonly associated with particular unsafe acts than others, and some systemic factors more commonly associated with some workplace factors than others. This study shows that the causes of accidents are complicated and several factors need to be considered during accident investigations. There is a need to apply the framework on a wide range of accident reports from different mines.

\section{Acknowledgement}

This work is based on research supported by the South African Research Chairs Initiative of the Department of Science and Technology and National Research Foundation of South Africa, which is gratefully acknowledged.

Any opinion, finding, and conclusion or recommendations expressed in this material is that of the authors and the NRF does not accept any liability in this regard.

\section{References}

Ashworth, S.G.E. and Peake, A.V. 1994. Assessment of the dominant circumstances and factors giving rise to accidents in the gold and platinum mining industries. Safety in Mines Research Advisory Committee, GAP 055, March, 1994. http://hdl.handle.net/10204/1687 [Accessed 25 April 2015].

BAYSARI, M.T., McInToSH, A.S., and WiLSON, J. 2008. Understanding the human factors contribution to railway accidents and incidents in Australia. Accident Analysis and Prevention, vol. 40. pp. 1750-1757

Bonsu, J., van Dyk, W., Franzidis, J-P., Petersen, F., and Isafiade, A. 2015. A systems approach to mining safety: an application of the Swiss Cheese model. Journal of the Southern African Institute of Mining and Metallurgy, vol. 116 , no. 8. pp. $776-784$.
Bullock, M.G. 1979. Work Process Control Guide, System Safety Development Centre. EGandG Idaho, Inc. Idaho Falls, Idaho.

CAwLEY, J.C. 2003. Electrical accidents in the mining industry, 1990-1999. IEEE Transactions on Industry Applications, vol. 39, no. 6. pp. 1570-1577.

Chamber of Mines South Africa. 2013. Facts and Figures. https://commondatastorage.googleapis.com/comsa/facts-and-figures-2013.pdf [Accessed 1 September 2014].

Chamber of Mines South Africa. 2012. Facts and Figures. https://commondatastorage.googleapis.com/comsa/facts-and-figures-2012.pdf [Accessed 20 April 2015].

CSIR. 2007. Occupational health and ergonomics. http://www.csir.co.za/mineral_resources/ohe.html [Accessed 5 February 2013].

Department of Mineral Resources. 2007. South African Mines Reportable Accidents Statistics System. http://www.dmr.gov.za/samrasscodebook/summary/143-occupational-safety/594-samrasscodebook-formines2007.html [Accessed 1 September 2012].

Holnnagel, E. 2008. Risk + barriers = safety? Safety Science, vol. 46, no. 2. pp. 221-229.

JANSEN, J.C. and BRENT, A.C. 2005. Reducing accidents in the mining industryan integrated approach. Journal of the South African Institute of Mining and Metallurgy, vol. 105. pp. 719-726.

Kecojevic, V., Komljenovic D., Groves W., and Radomsky, M. 2007. An analysis of equipment-related fatal accidents in U.S. mining operations: 19952005. Safety Science, vol. 45, no. 8. pp. 864-874.

Lenné, M.G., SAlmon, P.M., Liu, C.C., and Margaret, M. 2011. A systems approach to accident causation in mining: An application of the HFACS method. Accident Analysis and Prevention Journal. doi:10.1016/j.aap.2011.05.026

LI, W.C. and HARRIS, D. 2006. Pilot error and its relationship with higher organizational levels: HFACS analysis of 523 accidents. Aviation, Space and Environmental Medicine, vol. 77. pp. 1056-1061.

LI, W.C., HARRIS, D., and YU, C.S. 2008. Routes to failure: analysis of 41 civil aviation accidents from the Republic of China using the human factors analysis and classification system. Accident Analysis and Prevention, vol. 40. pp. 426-434.

Mail AND GuARdian. 2011. SA mines face shutdown over deaths. 15 April. http://mg.co.za/article/2011-04-15-sa-mines-face-shutdown-over-deaths [Accessed 1 February 2013].

MASIA, U. and PIENAAR, J. 2011. Unraveling safety compliance in the mining industry: examining the role of work stress, job insecurity, satisfaction and commitment as antecedents. SA Journal of Industrial Psychology/SA Tydskrif vir Bedryfsielkunde, vol. 37, no. 1. Article 937, 10 pp.

Moseme, R., Foster, P.J., Demana, R.L., and RuPPRecht, S.M. 2003. Investigation into the causes of accidents on scraper systems in the gold and platinum mining sectors. CSIR Miningtek and Camborne School of Mines, Pretoria/UK.

Patterson, J.M. and Shappell, S.A. 2008. Analysis of mining accidents in Queensland, Australia from 2004 to 2008 using HFACS-MI. http://www.nost.edu.au/icms_docs/143965_Report_Analysing_Human_Fa tors_in_Old_Mine_Incidents_HFACS_-_MI.pdf [Accessed 23 July 2015]

PATterson, J.M. and Shappell, S.A. 2010. Operator error and system deficiencies: Analysis of 508 mining incidents and accidents from Queensland, Australia using HFACS. Accident Analysis and Prevention, vol. 42, no. 4. pp. 1379-1385.

PAUL, P.S. and MAITI, J. 2008: The synergic role of sociotechnical and personal characteristics on work injuries in mines. Ergonomics, vol. 51, no. 5. pp. 737-767.

REAson, J. 1990. Human Error. Cambridge University Press.

REASON, J. 1997. Managing the Risks of Organizational Accidents. Ashgate.

REASON, J., PARKER, D., and LAWTON, R. 1998. Organizational controls and safety: The varieties of rule-related behaviour. Journal of Occupational and Organizational Psychology, vol. 71, pp. 289-304.

REASON, J. 2000. Safety paradoxes and safety culture. Injury Control and Safety Promotion, vol. 7, no. 1. pp. 3-14.

Ryan, B. 2008. Mine safety a threat to SA's economy. Mining MX higher grade. http://www.miningmx.com page/news/archive/179999-Mine-safety-athreat-to-SA-s-economy\#.UQvOAGdnDF8 [Accessed 1 February 2013]

SALEH, J.H. and Cummings, A.M. 2011. Safety in the mining industry and the unfinished legacy of mining accidents: Safety levers and defense-in-depth for addressing mining hazards. Safety Science, vol. 49, no. 6. pp. 764-777.

SAnmiouel, L., Freijo, M., Edo, J., and Rossel, J.M. 2010. Analysis of work related accidents in the Spanish mining sector from 1982-2006. Journal of Safety Research, vol. 41. pp. 1-7.

Souelch, A.P. 2001. Virtual reality for mine safety training in South Africa. Journal of the South African Institute of Mining and Metallurgy, vol. 101. pp. 209-216.

Teleka, S.R., Green, J.J., BrinK, S., Sheer, J., and Hlophe, K. 2012. The automation of the 'making safe' process in South African hard-rock underground mines. International Journal of Engineering and Advanced Technology (IJEAT), vol. 1, no. 4. pp 1-7. 